\title{
Patterns of international collaboration in nursing and palliative research
}

\author{
Tsair-Wei Chien ${ }^{1,2}$, Yu Chang ${ }^{3}$ and Wei-Chih Kan ${ }^{4 *}$ \\ ${ }^{1}$ Research Department, Chi-Mei Medical Center, Tainan, Taiwan \\ ${ }^{2}$ Department of Hospital and Health Care Administration, Chia-Nan University of Pharmacy and Science, Tainan, Taiwan \\ ${ }^{3}$ National Taiwan University School of Medicine, Taiwan \\ ${ }^{4}$ NcphrologyDepartment, Chi-Mei Medical Center, Tainan, Taiwan
}

\begin{abstract}
Objective: To investigate patterns of international collaborations in nursing and palliative research by collecting data from Medline and to visualize data using Google maps and social network analysis(SNA).

Methods: Selecting 378 abstracts, author names, countries, keywords, and medical subject headings (MESH) on November 22, 2017 from the Medline in terms of title with nursing and palliative, we reported following features: (1) nation and journal distribution in papers regrading nursing and palliative; (2) research features represented by paper author-defined keywords and MESH terms. We programmed Microsoft Excel VBA routines to extract data from Medline. Google Maps and SNA Pajek software were performed to display visualized representations for this study.

Results: We found that (1) the most number of papers regarding nursing and palliative are from nations of U.S. (105, 37.23\%) and U.K. (41, 14.54\%);(2) the most number of journals in production of nursing and palliative are Int J Palliat Nurs (54, 14.29\%) and J Palliat Med (21, 14.29\%); (3) the most linked keywords are palliative care and nursing home; (4) the most linked MESH terms are nursing homes and palliative care.

Conclusions: Social network analysis provides wide and deep insight into the relationships among nations, coauthor collaborations, and abstract keywords. The results can be provided to strategy and decision making for readers in future.
\end{abstract}

\section{Introduction}

Comorbid is defined in medicine as existing simultaneously with and usually independently of another medical condition. In hospital settings, palliative care and cancer care patient are often combined and occurred together $[1,2]$. As for palliative care nursing, patient care of knowledge and attitude are also commonly and often co-occurred with one another $[3,4]$. In many situations, it is very hard to observe the association of two or more symptoms at one moment.

An apocryphal story often told to illustrate the concept of cooccurrence is about beer and diaper sales. It usually goes along with both beer and diaper sales which were strongly correlated [5-7] in a market place. All possible pairs of our observed phenomena or entities can be combined and analyzed using computer techniques. However, we have not seen any computer algorithms telling us how to select the most possible pairs co-occurred in a system.

\section{Social network analysis(SNA)}

Social network analysis(SNA) [8-10] has been applied to authorship collaboration in recent years. Co-authorship among researchers can form a type of social network, called co-author network [11]. We are thus interested in using SNA to explore the most pair relations (e.g., beer and diaper in a marking sale) for a topic such as nursing and palliative from data we observed and collected.

\section{Author collaborations and international relations}

Many papers have been collected and saved at the US National Library of Medicine National Institutes of Health(Pubmed.com).
However, we have not seen any using Google maps to show their study results in literature even if some computer scientists have placed high hope on those machine-learning algorithms, data mining or artificial intelligence to quantify research information $[12,13]$. Extracting the Pubmed (or say Medline) published papers may be a way to show some important information of a specific topic(eg, nursing and palliative) on google maps, especially for the reason that using internet information to increase the yield of knowledge from data generated in the course of inquiry[14-16]. How to display our results on Google maps is required to explore and study.

\section{Aims of the study}

Our aims are to investigate patterns of international collaborations in nursing and palliative research by collecting data from Medline and to visualize results in following representations: (i) nation and journal distribution in papers regrading nursing and palliative; (ii) research features represented by paper author-defined keywords and medical subject headings (MESH) terms.

Correspondence to: Wei-Chih Kan, Nephrology Department, Chi-Mei Medical Center, 901 Chung Hwa Road, Yung Kung Dist., Tainan 710, Taiwan, E-mail: rasch. smile@gmail.com

Key words: abstract keywords, authorship collaboration, Google maps, social network analysis, Medline

Received: December 02, 2017; Accepted: December 19, 2017; Published: December 22, 2017 


\section{Methods}

\section{Data sources}

We programed Microsoft Excel VBA (visual basic for applications) modules for extracting abstracts and their corresponding coauthor names as well as keywords on November 22, 2017 from the US National Library of Medicine National Institutes of Health(Medline). Only those abstracts entitled with nursing and palliative and labelled with Journal Article were included. Others like those labelled with Published Erratum, Editorial or without author nation name were excluded from this study. A total of 378 eligible abstracts were obtained from Medline since 1990 .

\section{Data arrangement to fit SNA requirement}

We analyzed 378 papers with complete data including author countries, author-defined keywords, and article MESH terms. Prior to visualize representations of research findings using SNA, we organized data in compliance with the SNA format and guidelines using Pajek software [17]. Microsoft Excel VBA was used to deal with data fitting to the SNA requirement.

\section{Graphical representations to report}

\section{Author nations and their relations}

Two cross tables (ie. columns for publication years and rows for the $1^{\text {st }}$ author nations as well as journals) were produced presenting the distribution of nations and the most number of journals publishing papers of nursing and palliative. The bigger bubble means the more number of the nodes (ie, nations, keywords, or MESH terms in this study). The wider line indicates the stronger relations between two nodes. Community clusters are filled with different colors in bubbles.

\section{Keywords and MESH terms to present the research domain}

If keywords represent the research domain, the stronger relations between two keywords can be highlighted by SNA, like the concept of co-occurrence about beer and diaper sales. The presentation for the bubble and line is interpreted similar to the previous section.

\section{Statistical tools and data analyses}

Google Maps [18] and SNA Pajek software [17] were used to display visualized representations for papers published in a relation to nursing and palliative. Author-made Excel VBA modules were applied to organize data.

\section{Results}

\section{Author nations and their relations}

A total of 282 eligible papers with complete author nations based on journal article since 1990 are shown in Table 1. We can see that the most number of papers are from nations of U.S. $(105,37.23 \%)$ and U.K. $(41,14.54 \%)$. The trend in the number of publications with authorship from countries is present in the column of correlation in Table 1. The diagram shown by SNA and Google Maps in Figure 1 displays author collaboration among nations based on terms of nursing and palliative in abstract title. The highest productive areas are from U.S. and Europe. Any nation collaborated with other nations are shown with a blue line. Interested authors are recommend to click the bubble of interest to see details on a website at reference [19] (Table 1 and Figure 1).

\section{Journals and the trend}

The most number of journals in production of nursing and palliative are from Int J Palliat Nurs (54, 14.29\%) and J Palliat Med (21, $14.29 \%)$. The trend in the number of publications for a journal is shown in the column of correlation in Table 2.

\section{Keywords to present the feature of research domain}

The most linked keywords are palliative care and nursing home, see Figure 2 or click it on the reference [20]. We can see that the two bigger bubbles are of palliative care and nursing home in the yellow cluster (Figure 2).

\section{MESH terms to present the feature of research domain}

The most linked MESH terms are nursing homes and palliative care see Figure 3 or click it on the reference [21]. We can see that the two bigger bubbles are of palliative care and nurse-patient relation in the yellow and green clusters.

\section{Discussion}

This study used SNA techniques to report: found that (1) U.S.(105, $37.23 \%)$ and U.K.(41, 14.54\%) are nations with the most number of papers entitled nursing and palliative; (2) the most number of journals publishing papers of nursing and palliative are Int J Palliat Nurs (54, 14.29\%) and J Palliat Med (21, 14.29\%); (3) the most linked keywords are palliative care and nursing home; (4) the most linked MESH terms are nursing homes and palliative care.

\section{What this adds to what was known}

Many previous researches [8-10] have investigated coauthor collaboration using SNA. An apocryphal story often told to discover the co-occurrence about beer and diaper sales [5-7]. However, we have not seen any that can d0emonstrate a concrete way to show how to conduct such an exploration and to present informative messages to readership. We showed that incorporating SNA with Google Maps is an easy way to isplay all possible pairs of our observed phenomena at a short moment.

Journal authorship collaboration can be compared with each other using Google Maps. We can see that many links connecting two nations which indicate a collaboration pattern in paper publication similar to the previous study [8]. Hence the researchers have many international author collaborations in the subject category of of nursing and palliative which is inconsistent with the previous studies that investigated scientific collaboration of Iranian Psychology and Psychiatry Researchers [22,23].

There are 1611 papers with the keyword social network analysis in paper title when searching Pubmed database in 2017 September 1. Only two papers [24,25] incorporated $\mathrm{MeSH}$ into social network analysis to explore interesting informative knowledge. However, no any that can incorporate Google maps in a study to show more value information like the current study. The way we illustrated the strongest relation in all possible couples of interests is novel and promising in future, especially in the field of nursing and palliative fields.

\section{What it implies and what should be changed?}

Scientific publication is one of the objective measurements to evaluate the achievements of a medical specialty or discipline [26]. It is worth using SNA and Google Maps to report journal features in future. 
Chien TW (2017) Patterns of international collaboration in nursing and palliative research

Table 1. Nation distribution based on the 1st author for papers regarding nursing and palliative.

\begin{tabular}{|c|c|c|c|c|c|c|c|c|c|c|c|c|c|c|}
\hline Nation & $1990-2007$ & 2008 & 2009 & 2010 & 2011 & 2012 & 2013 & 2014 & 2015 & 2016 & 2017 & Total & Corr. & $\%$ \\
\hline U.S & 40 & 9 & 4 & 9 & 3 & 6 & 6 & 2 & 7 & 8 & 11 & 105 & 0.21 & 37.23 \\
\hline U.K & 24 & 3 & 2 & 3 & & 1 & 2 & & 1 & 4 & 1 & 41 & -0.18 & 14.54 \\
\hline Australia & 12 & 2 & 2 & 1 & & 1 & 1 & 1 & 4 & & 2 & 26 & 0.06 & 9.22 \\
\hline Canada & 14 & 1 & 1 & 2 & 2 & 2 & 1 & & & 1 & 1 & 25 & -0.42 & 8.87 \\
\hline Sweden & 2 & 2 & & & & & 1 & 3 & 1 & 1 & 3 & 13 & 0.48 & 4.61 \\
\hline Ireland & 4 & & & & & 2 & & 1 & 1 & 1 & & 9 & 0.34 & 3.19 \\
\hline France & 2 & 1 & 1 & & & & & 1 & 1 & & & 6 & -0.28 & 2.13 \\
\hline Germany & 1 & & & 1 & 1 & & 1 & & & & 2 & 6 & 0.29 & 2.13 \\
\hline Belgium & 0 & & & & & & & 2 & & 1 & 2 & 5 & 0.67 & 1.77 \\
\hline Brazil & 0 & & & & & & 2 & & & 2 & 1 & 5 & 0.54 & 1.77 \\
\hline Netherlands & 3 & 1 & & 1 & & & & & & & & 5 & -0.61 & 1.77 \\
\hline Spain & 1 & & & & & & & 1 & & 2 & 1 & 5 & 0.68 & 1.77 \\
\hline Taiwan & 0 & & 1 & & & 1 & & & 2 & & 1 & 5 & 0.29 & 1.77 \\
\hline Denmark & 0 & 1 & & 1 & 1 & & & & 1 & & & 4 & -0.43 & 1.42 \\
\hline Austria & 1 & & & & & & & 1 & & & 1 & 3 & 0.52 & 1.06 \\
\hline Japan & 1 & & & 1 & & & & & & & 1 & 3 & 0.17 & 1.06 \\
\hline India & 0 & & & 1 & 1 & & & & & & & 2 & -0.35 & 0.71 \\
\hline Italy & 0 & & & & & & & 1 & & & 1 & 2 & 0.52 & 0.71 \\
\hline Portugal & 0 & & & & 1 & & & & & 1 & & 2 & 0.17 & 0.71 \\
\hline Saudi Arabia & 0 & & & & & & & & & & 2 & 2 & 0.52 & 0.71 \\
\hline Finland & 0 & & & & & & & & & & 1 & 1 & 0.52 & 0.35 \\
\hline Iran & 0 & & & & & & & & & & 1 & 1 & 0.52 & 0.35 \\
\hline Lebanon & 0 & & 1 & & & & & & & & & 1 & -0.41 & 0.35 \\
\hline Lithuania & 0 & & & & & & & 1 & & & & 1 & 0.17 & 0.35 \\
\hline New Zealand & 0 & & & 1 & & & & & & & & 1 & -0.29 & 0.35 \\
\hline Nigeria & 0 & & 1 & & & & & & & & & 1 & -0.41 & 0.35 \\
\hline Norway & 0 & & & 1 & & & & & & & & 1 & -0.29 & 0.35 \\
\hline Switzerland & 0 & & & & & & & & 1 & & & 1 & 0.29 & 0.35 \\
\hline Total & 105 & 20 & 13 & 22 & 9 & 13 & 14 & 14 & 19 & 21 & 32 & 282 & 0.46 & 100.00 \\
\hline
\end{tabular}

Table 2. Journal distribution for papers regarding nursing and palliative.

\begin{tabular}{|c|c|c|c|c|c|c|c|c|c|c|c|c|c|c|}
\hline Journals & 1990-2007 & 2008 & 2009 & 2010 & 2011 & 2012 & 2013 & 2014 & 2015 & 2016 & 2017 & Total & Corr. & $\%$ \\
\hline Int J Palliat Nurs & 25 & 5 & 5 & 3 & 3 & & 1 & 4 & 2 & 1 & 5 & 54 & -0.29 & 14.29 \\
\hline J Palliat Med & 11 & 2 & & & & 1 & 3 & & 1 & 1 & 2 & 21 & 0.24 & 5.56 \\
\hline J Adv Nurs & 9 & 2 & & & & 2 & & & & & & 13 & -0.44 & 3.44 \\
\hline Br J Nurs & 6 & 2 & & & & 1 & & & & 1 & 1 & 11 & -0.08 & 2.91 \\
\hline Palliat Med & 7 & & & & & 1 & 2 & & & 1 & & 11 & 0.21 & 2.91 \\
\hline J Clin Nurs & 2 & & 2 & 3 & & & & & 1 & 1 & 1 & 10 & -0.14 & 2.65 \\
\hline $\begin{array}{c}\text { Am J Hosp Palliat } \\
\text { Care }\end{array}$ & 2 & 1 & & & & & & & & 3 & 2 & 8 & 0.51 & 2.12 \\
\hline $\begin{array}{c}\text { J Am Med Dir } \\
\text { Assoc }\end{array}$ & 2 & 1 & & 1 & 1 & & & 1 & 1 & & 1 & 8 & 0.00 & 2.12 \\
\hline $\begin{array}{c}\text { J Pain Symptom } \\
\text { Manage }\end{array}$ & 1 & & & 1 & 1 & & 1 & & 2 & 1 & 1 & 8 & 0.52 & 2.12 \\
\hline J Palliat Care & 6 & & & & & & & 1 & & & 1 & 8 & 0.52 & 2.12 \\
\hline Nurse Educ Today & 2 & 1 & & & & & & 1 & 2 & 1 & & 7 & 0.29 & 1.85 \\
\hline $\begin{array}{l}\text { Palliat Support } \\
\text { Care }\end{array}$ & 0 & 1 & 1 & 1 & & & & & 1 & & 3 & 7 & 0.21 & 1.85 \\
\hline $\begin{array}{c}\text { Gan To Kagaku } \\
\text { Ryoho }\end{array}$ & 4 & & & 1 & 1 & & & & & & & 6 & -0.35 & 1.59 \\
\hline Nurs Times & 4 & & 2 & & & & & & & & & 6 & -0.41 & 1.59 \\
\hline Pflege $Z$ & 2 & 2 & & 1 & & & 1 & & & & & 6 & -0.58 & 1.59 \\
\hline Soins & 3 & 1 & & & 1 & & & & 1 & & & 6 & -0.27 & 1.59 \\
\hline Clin J Oncol Nurs & 0 & & 1 & & 1 & & 1 & & & 1 & 1 & 5 & 0.24 & 1.32 \\
\hline J Prof Nurs & 1 & 2 & & & & & & & & 2 & & 5 & -0.09 & 1.32 \\
\hline BMC Palliat Care & 0 & & & & & & & & & 2 & 2 & 4 & 0.70 & 1.06 \\
\hline $\begin{array}{c}\text { Br J Community } \\
\text { Nurs }\end{array}$ & 2 & & 1 & & & & & 1 & & & & 4 & -0.17 & 1.06 \\
\hline Total & 145 & 27 & 21 & 26 & 12 & 15 & 15 & 25 & 24 & 24 & 41 & 378 & 0.03 & 100 \\
\hline
\end{tabular}




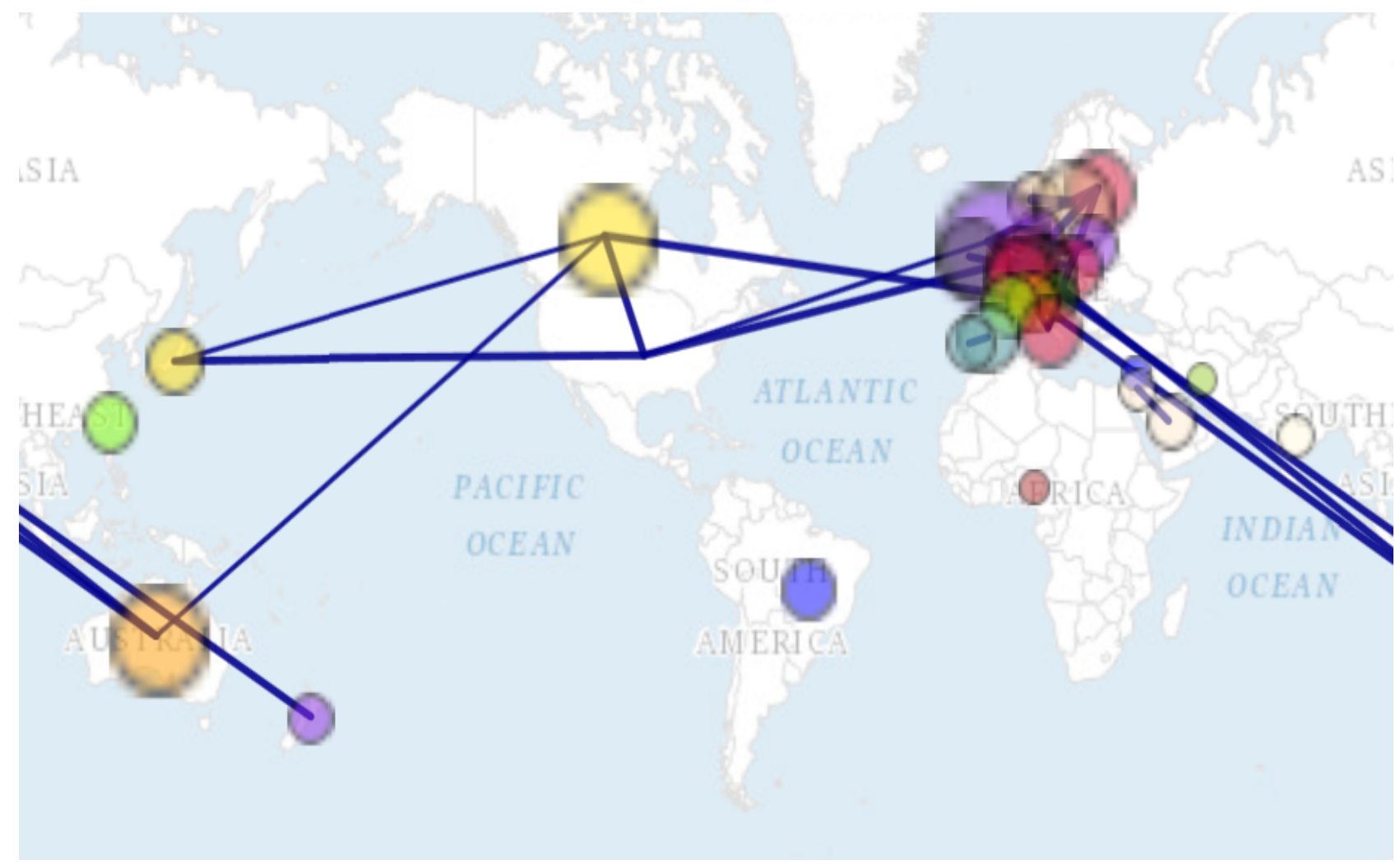

Figure 1. International coauthor collaboration in topics of nursing and palliative.

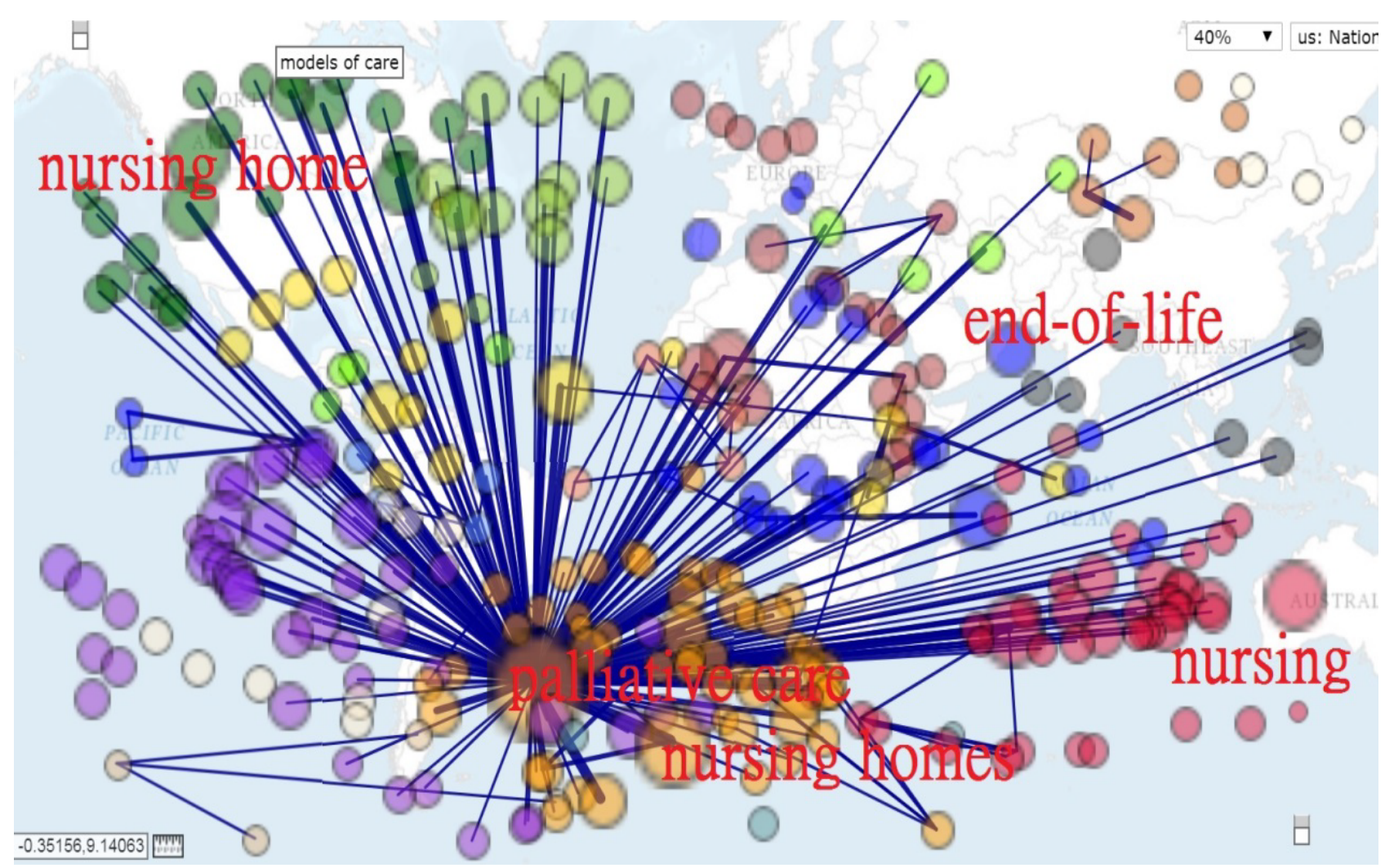

Figure 2. Keywords in papers regarding nursing and palliative. 


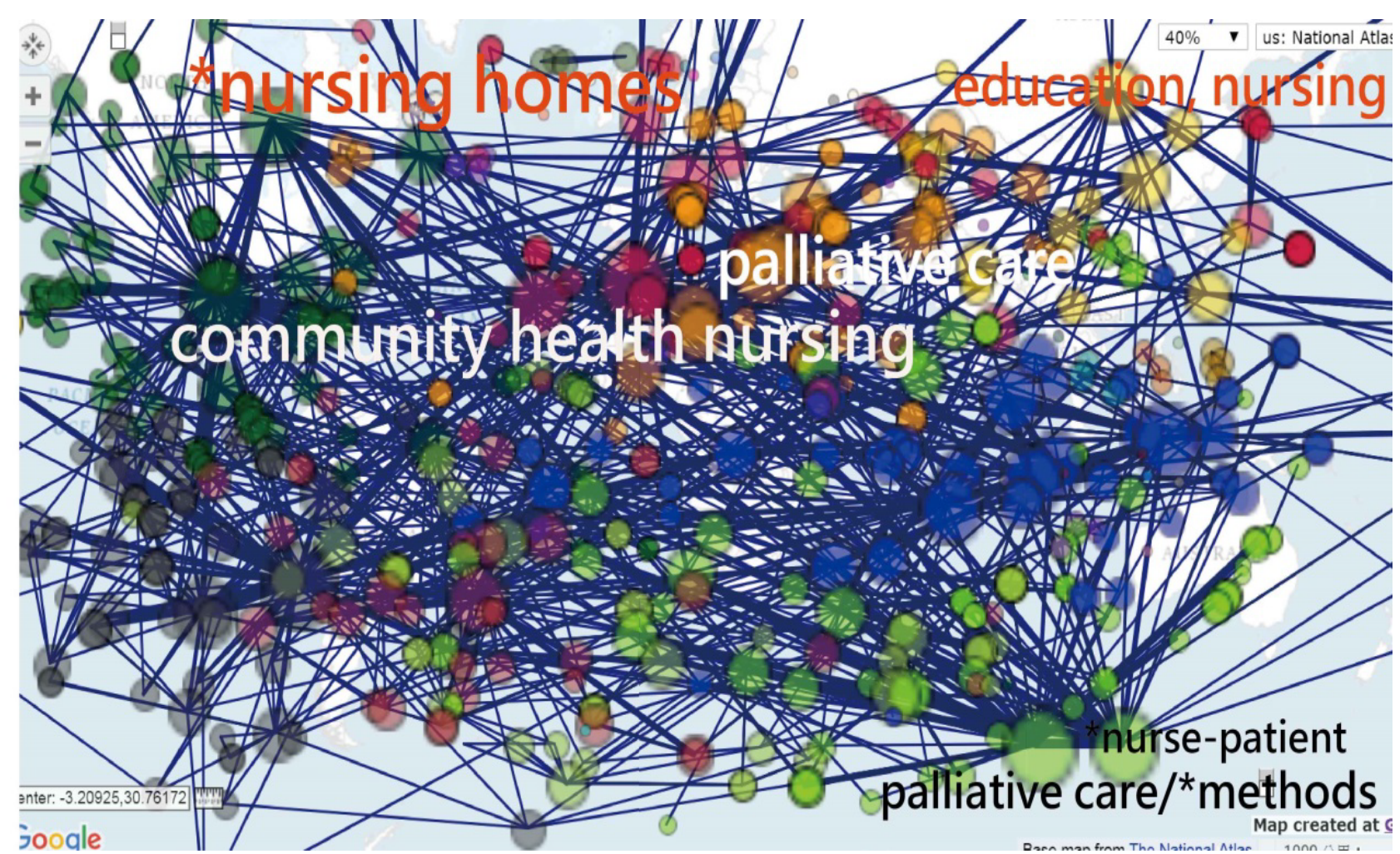

Figure 3. Mesh terms in papers regarding nursing and palliative.

Several algorithms and measures have been developed and used with SNA to graphically explore data. If we investigate whether any author or paper most fits the research domain of a journal and its scope within the journal's keyword network, the centrality measures using SNA can be applied [8]. It means that the core subject can be analyzed using the centrality measure $[23,27]$ yielded in SNA.

\section{Strengths of this study}

The way incorporating SNA with Google Maps is unique, which is never seen in other published papers [8-10] with a single SNA presentation. Another strength and feature for this study is the Google Maps used and linked in references [19-21] for interested readers who can quickly understand the features of the study. The nation distribution in Figure 1 is merit in easily understanding the feature of international collaborations for the topics of nursing and palliative. One picture is worth ten thousand words. We hope following studies can report more such kinds of information using SNA and Google Maps to readers in future.

\section{Limitations and future study}

The interpretation and generalization of the conclusions of this study should be carried out with caution. First, the data of this study were collected from Medline for a single journal. It is worth noting that any attempt to generalize the findings of this study should be made in the similar journal domain with similar topic and scope contexts.

Second, although the data were extracted from Medline and carefully dealt with every linkage as correct as possible, the original downloaded text file including some errors in symbols such as period and comma in author address that might lead to some bias in the resulting nation distribution.
Third, there are many algorithms used for SNA. We merely applied separation components showing in Figures. Any changes made along with algorithm used will present different pattern and judgment.

Fourth, the social network analysis is not subject to the Pajeck software we used in this study, Others such as Ucinet[28] and Gephi[29] are suggested to readers for use in future.

\section{Conclusion}

Social network analysis provides wide and deep insight into the relationships among nations, coauthor collaborations, and abstract keywords. The results can be provided to strategy and decision making for readers in future.

\section{References}

1. Stephens CE, Hunt LJ, Bui N, Halifax E, Ritchie CS, et al. (2017) Palliative Care Eligibility, Symptom Burden, and Quality-of-Life Ratings in Nursing Home Residents. JAMA Intern Med. [Crossref]

2. Smith D, Brown S (2017) Integrating a palliative care approach into nursing care homes for older people. Int J Palliat Nurs 23: 511-515. [Crossref]

3. Kirkpatrick AJ, Cantrell MA, Smeltzer SC (2017) A Concept Analysis of Palliative Care Nursing: Advancing Nursing Theory. ANS Adv Nurs Sci 40: 356-369.

4. Pan HH, Shih HL, Wu LF, Hung YC, Chu CM, et al. (2017) Path modeling of knowledge, attitude and practice toward palliative care consultation service among Taiwanese nursing staff: a cross-sectional study. BMC Palliat Care 16: 42.

5. Domingos p (2012) A few useful things to know about machine learning Communications of the ACM 55: 78-87.

6. Verhoef PC, Kooge E, Walk N (2016) Creating Value with Big Data Analytics: Making Smarter Marketing Decisions. London: Routledge.

7. Power DJ (2017) What is the "true story" about data mining, beer and diapers? DSS News.

8. Sadoughi F, Valinejadi A, Shirazi MS, Khademi R (2016) Social Network Analysis of Iranian Researchers on Medical Parasitology: A 41 Year Co-Authorship Survey. Iran J Parasitol 11: 204-212. 
9. Osareh F, Khademi R, Rostami MK, Shirazi MS (2014) Co-authorship Network Structure Analysis of Iranian Researchers' scientific outputs from 1991 to 2013 based on the Social Science Citation Index (SSCI). Collnet J Scientometr Info Manag 8: 263-271.

10. Liu X, Bollen J, Nelson ML, Van de Sompel H (2005) Co-authorship networks in the digital library research community. Info Process Manag 41: 1462-1480.

11. Osareh F, Khademi R, Rostami MK, Shirazi MS (2014) Co-authorship Network Structure Analysis of Iranian Researchers' scientific outputs from 1991 to 2013 based on the Social Science Citation Index (SSCI). Collnet J Scientometr Info Manag 8: 263- 71.

12. Luo L, Li L, Hu J, Wang X, Hou B, et al. (2016) A hybrid solution for extracting structured medical information from unstructured data in medical records via a doublereading/entry system. BMC Med Inform Decis Mak 16: 114.

13. Knoblock CA, Lerman K, Minton S, Muslea I (2003) Accurately and reliably extracting data from the web: a machine learning approach. In: Intelligent exploration of the web. New York: Springer pp. 275-287.

14. Ohno-Machado L (2016) Data-driven informatics tools targeting patients and providers. J Am Med Inform Assoc 23: 1039.

15. Ohno-Machado L (2017) Advancing healthcare and biomedical research via new datadriven approaches. J Am Med Inform Assoc 24: 471. [Crossref]

16. Shah NH, Tenenbaum JD (2012) The coming age of data-driven medicine: translational bioinformatics' next frontier. J Am Med Inform Assoc 19: e2-4.

17. de Nooy W, Mrvar A, Batagelj V (2011) Exploratory Social Network Analysis with Pajek: Revised and Expanded (2nd Edn) New York, NY: Cambridge University Press.

18. Phan TG, Beare R, Chen J, Clissold B, Ly J, et (2017) Googling Service Boundaries for Endovascular Clot Retrieval Hub Hospitals in a Metropolitan Setting: Proof-ofConcept Study. Stroke 48: 1353-1361.
19. Chien TW (2017) Google Maps on author collaboration for nursing and palliative.

20. Chien TW (2017) Google Maps on author-defined keywords for nursing and palliative.

21. Chien TW (2017) Google Maps on MESH terms for nursing and palliative.

22. Erfanmanesh MA, Rohani VA, Basirian Jahromi R, Gholamhosseinzadeh Z (2013) Investigating Scientific Collaboration of Iranian Psychology and Psychiatry Researchers. J Info Process Manag 29: 137-163.

23. Osareh F, Norouzi Chakoli A, Keshvari M (2010) Co-authorship of Iranian researchers in science, social science, art and humanities citation indexes in the web of science between 2000 and 2006. J Info Sci Technol 25: 573-595.

24. Hu SK, Huang J, Hong WD, Du XJ, Jin R, et al. (2017) The 50 Most-cited Articles in Gastroenterology and Hepatology from Mainland China. Pak J Med Sci 33: 215-220.

25. Coelho DH, Edelmayer LW, Fenton JE (2014) A century of citation classics in otolaryngology-head and neck surgery journals revisited. Laryngoscope 124:13581362.

26. Chang HT, Lin MH, Hwang IH, Chen TJ, Lin HC, et al. (2017) Scientific publications in gastroenterology and hepatology in Taiwan: An analysis of Web of Science from 1993 to 2013. J Chin Med Assoc 80: 80-85.

27. Liu X, Bollen J, Nelson ML, Van de Sompel H (2005) Co-authorship networks in the digital library research community. Info Process Manag 41: 1462-1480.

28. Borgatti SP, Everett MG, Freeman LC (2002) Ucinet for Windows: Software for Social Network Analysis. Harvard, MA: Analytic Technologies.

29. Bastian M, Heymann S, Jacomy M (2009) Gephi: an open source software for exploring and manipulating networks. International AAAI Conference on Weblogs and Social Media.

Copyright: $\odot 2017$ Chien TW. This is an open-access article distributed under the terms of the Creative Commons Attribution License, which permits unrestricted use, distribution, and reproduction in any medium, provided the original author and source are credited. 